\title{
The Role of Autonomic Dysregulation from Pathophysiology to Therapeutics of Multiple Sclerosis: A Putative Novel Treatment Target?
}

Juan Manuel Racosta and Marcelo Kremenchutzky

Department of Clinical Neurological Sciences, London Health Sciences Centre, Western University, London, ON, Canada

*Corresponding author: Marcelo Kremenchutzky, 339 Windermere Road, P.O. Box 5339 London ON, Canada, N6A 5A5, Tel: 519- 685-8500; Fax: 519-663-3744; Email: marcelo.kremenchutzky@lhsc.on.ca

Received date: Feb 23, 2014, Accepted date: May 21, 2014, Published date: May 27, 2014

Copyright: (c) 2014 Racosta JM, et al. This is an open-access article distributed under the terms of the Creative Commons Attribution License, which permits unrestricted use, distribution, and reproduction in any medium, provided the original author and source are credited.

\begin{abstract}
Autonomic Nervous System (ANS) dysfunction (AuD) is a common cause of disability in people living with Multiple Sclerosis (MS), but clinical manifestations are heterogeneous and therapeutic options are lacking. AuD is implicated as having a possible role in the regulation of inflammation and neurodegeneration. Hence, treatments with drugs that affect the ANS may have an impact in the inflammatory and neurodegenerative processes intrinsic to MS, resulting in an intriguing and potentially significant novel therapeutic consideration. Additionally, just alike patients with most other chronic diseases, MS patients often are exposed to a broad range of treatments both disease-specific and due to complications or co-morbidities. Considering them into an integrated context affords the opportunity to understand and exploit their therapeutic potential.
\end{abstract}

Keywords: Multiple sclerosis; Autonomic dysfunction; Immune regulation; Clinical manifestations; Therapeutics

\section{Autonomic Dysfunction in MS: Physiopathology Implications}

$\mathrm{AuD}$ is a common cause of disability in MS patients, ranging from sphincter (bladder and bowel) dysfunction, to fatigue and cardiovascular autonomic dysfunction (CAD), among others. Both the sympathetic (SNS) and parasympathetic (PNS) nervous systems are frequently, albeit not always simultaneously, compromised [1].

Bladder dysfunction is reported by approximately $75 \%$ of people with MS. Filling symptoms (ie failure to store), such as increased frequency, urinary urgency and nocturia, and emptying symptoms, such as intermittency, weak stream and straining at the beginning of urination are the most common manifestations [2]. The lack of ability to inhibit the detrusor muscles controlling urination, leading to neurogenic detrusor overactivity has a high incidence in MS. Bowel disorders are also common in MS, They are present in more than $70 \%$ of MS patients and are markedly associated with low quality of life scores [3]. Bowel incontinence, diarrhea and constipation are the commonest manifestations [3], while the most frequent underlying disorders are poor anal sphincter control, gut motility and ano-rectal sensation/coordination [4].

Fatigue is arguably the commonest subjective complain in the MS population, reported in up to $90 \%$ of MS patients. It was linked to dysautonomia in some studies, pointing to a sympathetic vasomotor dysfunction with relative cardiovagal integrity [5] and a possible impairment of the sympathovagal balance consisting of a decrease of the vagal function and a normal to low sympathetic activity [6].

The frequency of CAD in the MS population is not well known, since most of the times is asymptomatic [1]. It can be assessed by hemodynamic tests based on heart rate variability (HRV) and blood pressure (BP) analysis. HRV is the physiological phenomenon of variation in the interval between heartbeats related mainly to the hemodynamic changes imposed by breathing and in blood vessel contraction. By measuring each beat-to-beat interval under conditions challenging the autonomic balance, such us sustained muscle contraction and Valsalva maneuver, among others, the amount and amplitude of variation can be calculated, and thus the PNS and SNS activity interpolated [7]. Cardiovascular SNS dysfunction is associated with clinically active MS relapses, while PNS dysfunction correlates with MS progression (relentless worsening independent from relapses) as measured by the expanded disability status score- EDSS [1-4,8,9].

\section{Dysregulation of ANS Mechanisms in MS}

SNS and PNS regulate neurotransmitters such as nor-epinephrine (NE), which activates the $\alpha$ - and $\beta$ - adrenergic receptors (AR, $\alpha \mathrm{AR}$, $\beta A R)$, and acetylcholine, which activates the muscarinic and nicotinic receptors. ANS and immune regulation have a bi-directional communication. As well as the brain plays a pivotal role in detecting and modulating inflammation through the ANS and the hypothalamic pituitary axis, the immune system dynamically regulates the ANS [9]. Hence, it is arguable that AuD may play a role in the immune regulation in chronic inflammatory diseases. According to the conventional picture in MS, the primary peripheral activation of autoreactive Th1 lymphocytes precedes the recognition of central nervous system auto-antigens, leading to the release of Th1 (pro-inflammatory) cytokines [10], which in turn produce an activation of the SNS. Then, the SNS exerts a negative feedback to the inflammatory response, triggering a switch to Th2 anti-inflammatory pathways $[11,12]$. These mechanisms generate a sequential decrease in SNS activity occurring in relapses, and a progressive decline in the noradrenergic axis over time, in parallel with an initially predominant Th1 inflammatory response, switching over the course of the disease to a rather Th2 predominant activity [13]. However this paradigm was challenged by new insights in diverse interrelated ways. First, recent findings implicated novel CD4+ T-cell subsets (TH17, TH9, T regulatory cells Tregs-) in MS physiopathology [14,15]. Second, despite the role of $\beta A R$ and lymphocytes endogenous catecholamine's seems relevant in 
all the lymphocyte sub-sets, their effects depend on the time of exposure and the degree of cell differentiation and activation. While mediating anti-inflammatory effects in most CD4+ TH cells, they enhance immune responses in specific Treg cell fractions $(\mathrm{CD} 4+\mathrm{CD} 25$ high $\mathrm{T}$ cells) [16]. Finally, less is known regarding the specific contribution in MS of the various AR subtypes ( $\alpha 1-\alpha 2-\beta 3$-ARs), some of them likely to promote inflammatory and neurodegenerative processes $[17,18]$.

PNS dysfunction may also exert influence in immune regulation in MS. The activation of the Vagus nerve culminates in the activation of the nicotinic acetylcholine receptor subunit $\alpha 7$ ( $\alpha 7 \mathrm{nAChR})$, which in turn leads to an anti-inflammatory response through the release of type II cytokines. It was suggested that the dysfunction of the cholinergic anti-inflammatory pathway can exacerbate inflammatory responses in various pathological conditions [19]. However there is limited knowledge regarding its contribution to immune regulation in MS. Despite evidence suggestive of anti-inflammatory signaling via a7nAChR in animal models, the PNS ability to counteract inflammation might be weak [20], and its dysfunction secondary to the underlying pathology of MS, rather than a factor involved in its development.

\section{Therapeutics and Putative Novel Targets for MS Treatment}

AR agonists and antagonists are used by their ability to treat a variety of diseases such as hypertension, congestive heart failure and asthma. The pharmacological modulation of adrenergic pathways can also be obtained by use of indirectly acting agents on all the steps involved in noradrenaline and adrenaline synthesis and metabolism. By modifying the central and peripheral NE activity, the inflammatory milieu can also be potentially regulated [1-5]. B-Blockers (ie bisoprolol, carvedilol, metoprolol) and angiotensin-converting enzyme inhibitors (ie losartan) reduce the NE circulating levels. They showed to decrease the Th1/Th2 cytokine ratios and inflammatory cytokine production in patients with chronic heart failure [21]. The expected effect of these drugs varies depending on the stage of the disease, age and gender of the patients (ie more pronounced in females). While these effects may be beneficial by normalizing the initially higher SNS tone in MS, they could also be detrimental by worsening SNS dysfunction in certain late or advanced cases [22]. Tricyclic antidepressant agents (TCA) also affect the sympathetic activation. While they centrally inhibit the sympathetic outflow, in the periphery they block its re-uptake. Therefore, they might reduce central NE, while increasing peripheral NE [13]. Increasing peripheral NE levels through the use of TCA demonstrated sensory, motor and autonomic symptoms improvements in MS patients [23]. Also HMG-CoA reductase inhibitors (statins), widely prescribed as cholesterollowering agents, reduce plasma noradrenaline [24]. They were proposed as a treatment option for MS, due to their immune modulatory effects [25], but failed to demonstrate efficacy [26]. Lack of consideration of important aspects, such as pre-treatment with IFN$\beta$, and heterogeneous clinical status among participants are listed as possible causes for the differing clinical outcomes when testing this drug [13]. Manipulation of the GABA pathway by diverse agents also inhibited inflammation in human and murine experimental autoimmune encephalomyelitis (EAE) [27]. The GABA-B receptor agonist baclofen reduces the NA neurotransmission from adrenergic nerve terminals [28], and the release of NE in the cerebral cortex [29]. Also Benzodiazepines reduce NE plasma levels [30] in humans, and it release in the prefrontal cortex of rats [31]. Finally Gabapentin and Pregabalin also inhibited NE release in the brain [27,32]. Despite this, there is still little evidence regarding the involvement of the GABA system in inflammatory mechanisms in MS.

On the contrary, other agents showed ability to increase CNS sympathetic activity. Among them Modafinil up-regulates the CNS NE levels [33] and antidepressants such as MAO inhibitors and SSR inhibitors increase CNS NE levels by inhibiting re-uptake.

More obscure mechanisms are implied with drugs acting on less characterized adrenergic receptors. Clonidine, a centrally-acting agent, which induces activation of CNS $\alpha 2 \mathrm{AR}$, may promote CNS neurodegenerative processes through the activation of MAP kinases [18].

Clonidine and Tizanidine demonstrated to decrease TNF- $\alpha$ in specific brain regions and inhibiting other Th1 cytokines [34], as a2AR are also capable of inhibiting Th1 cytokines and reducing both peripheral and central NE levels [34].

PNS tone also is modified by direct stimulation of the Vagus nerve or by pharmacological stimulation of both central muscarinic receptors and nicotinic $a 7 \mathrm{nAChR}$ in the periphery. PNS modulation also demonstrated potential for immune regulatory effects. The electrical stimulation of the Vagus nerve attenuated inflammation in a cytokine-dependent rat model of inflammatory disease by inhibiting Th1 cytokines release [35]. The use of an $\alpha 7 \mathrm{nAChR}$ selective agonist (GTS-21) also inhibited the cytokine production in human leukocytes [36]. On the other hand, the decrease of the PNS tone showed opposite effects. In one study based in a mice model of pancreatitis, both vagotomy and the use of a nicotinic receptor antagonist worsen the outcomes, while an $a 7 \mathrm{nAChR}$ agonist strongly decreased the severity of the disease [37]. Similar findings were made in models of lipopolysaccharide-induced inflammatory responses in mouse lung [38] experimental arthritis, ileus and hemorrhagic shock in pre-clinical experimentation [19]. The evidence in experimental models of MS is limited, and studies of parasympathetic modulation in inflammatory CNS diseases in humans are still lacking.

Since recent information provides new perspectives regarding the interaction between the ANS and the immune system, the immunoregulatory effects of other non-pharmacological therapies in MS, such as cooling, biofeedback, acupuncture, hypnosis, meditation and Pavlovian conditioning, should be weighted when considering their effects in the ANS. The beneficial impact of cooling in MS symptoms was demonstrated long time ago, with methods ranging from cold showers, regional cooling devices, cold beverages and cooling garments [39]. Taking into account that the beneficial effect was restricted by detrimental effect on the cardiovascular system, and that it is well known that cooling affects the ANS [40], future research should address this approach considering the impact on the ANS. The effect of biofeedback, acupuncture, hypnosis, meditation and Pavlovian conditioning should be considered under same circumstances.

People living with MS have ANS dysfunction early in the course of the disease and are often treated with drugs affecting the ANS, and potentially the inflammatory and neurodegenerative processes. The complex nature of these interactions remains incompletely understood and deserves further investigation. Treating physicians and patients alike should be more aware of the implications of ANS dysfunction in MS. 


\section{References}

1. McDougall AJ, McLeod JG (2003) Autonomic nervous system function in multiple sclerosis. J Neurol Sci 215: 79-85.

2. Fowler CJ, Panicker JN, Drake M, Harris C, Harrison SC, et al. (2009) Watkiss and M. Wells. 2009. "A UK Consensus on the Management of the Bladder in Multiple Sclerosis." J Neurol Neurosurg Psychiatry 80: 470-477.

3. Nortvedt MW, Riise T, Frugård J, Mohn J, Bakke A, et al. (2007) Prevalence of bladder, bowel and sexual problems among multiple sclerosis patients two to five years after diagnosis. Mult Scler 13: 106-112.

4. Wiesel PH, Norton C, Glickman S, Kamm MA (2001) Pathophysiology and management of bowel dysfunction in multiple sclerosis. Eur J Gastroenterol Hepatol 13: 441-448.

5. Flachenecker P, Rufer A, Bihler I, Hippel C, Reiners K, et al. (2003) Fatigue in MS is related to sympathetic vasomotor dysfunction. Neurology 61: 851-853.

6. Keselbrener L, Akselrod S, Ahiron A, Eldar M, Barak Y, et al. (2000) "Is Fatigue in Patients with Multiple Sclerosis Related to Autonomic Dysfunction?" Clin Auto Res 10: 169-175.

7. Hale LA, Nukada H, Du Plessis LJ, Peebles KC (2009) "Clinical Screening of Autonomic Dysfunction in Multiple Sclerosis." Physiother Res Int 14: $42-55$.

8. Flachenecker P, Reiners K, Krauser M, Wolf A, Toyka KV (2001) Autonomic dysfunction in multiple sclerosis is related to disease activity and progression of disability. Mult Scler 7: 327-334.

9. Watkins LR, Maier SF (2005) Immune regulation of central nervous system functions: from sickness responses to pathological pain. J Intern Med 257: 139-155.

10. Zoukos Y, Kidd D, Woodroofe MN, Kendall BE, Thompson AJ, et al. (1994) Increased expression of high affinity IL-2 receptors and betaadrenoceptors on peripheral blood mononuclear cells is associated with clinical and MRI activity in multiple sclerosis. Brain 117: 307-315.

11. Elenkov IJ, Wilder RL, Chrousos GP, Vizi ES (2000) The sympathetic nerve--an integrative interface between two supersystems: the brain and the immune system. Pharmacol Rev 52: 595-638.

12. Hasko G, Elenkov IJ, Kvetan V, Vizi ES (1995) "Differential Effect of Selective Block of Alpha 2-Adrenoreceptors on Plasma Levels of Tumour Necrosis Factor-Alpha, Interleukin-6 and Corticosterone Induced by Bacterial Lipopolysaccharide in Mice." J Endocrinol 144: 457-462.

13. Sternberg Z (2012) Sympathetic nervous system dysfunction in multiple sclerosis, linking neurodegeneration to a reduced response to therapy. Curr Pharm Des 18: 1635-1644.

14. Fletcher JM, Lalor SJ, Sweeney CM, Tubridy N, Mills KH (2010) "T Cells in Multiple Sclerosis and Experimental Autoimmune Encephalomyelitis." Clin Exp Immunol 162: 1-11.

15. Jager A, Dardalhon V, Sobel RA, Bettelli E, Kuchroo VK (2009) "Th1, Th17, and Th9 Effector Cells Induce Experimental Autoimmune Encephalomyelitis with Different Pathological Phenotypes." J Immunol 183: 7169-7177.

16. Cosentino M, Marino F (2013) Adrenergic and dopaminergic modulation of immunity in multiple sclerosis: teaching old drugs new tricks? J Neuroimmune Pharmacol 8: 163-179.

17. Grisanti LA, Woster AP, Dahlman J, Sauter ER, Combs CK, et al. (2011) "Alphal-Adrenergic Receptors Positively Regulate Toll-Like Receptor Cytokine Production from Human Monocytes and Macrophages." J Pharmacol Exp Ther 338: 648-657.

18. Lorton D, Lubahn C, Bellinger DL (2003) Potential use of drugs that target neural-immune pathways in the treatment of rheumatoid arthritis and other autoimmune diseases. Curr Drug Targets Inflamm Allergy 2: 1-30.

19. Tracey KJ (2009) Reflex control of immunity. Nat Rev Immunol 9: 418-428.

20. Nicolussi EM, Huck S, Lassmann H, Bradl M (2009) The cholinergic anti-inflammatory system limits $\mathrm{T}$ cell infiltration into the neurodegenerative CNS, but cannot counteract complex CNS inflammation. Neurobiol Dis 35: 24-31.

21. Gage JR, Fonarow G, Hamilton M, Widawski M, Martinez-Maza O, et al. (2004) "Beta Blocker and Angiotensin-Converting Enzyme Inhibitor Therapy is Associated with Decreased Th1/Th2 Cytokine Ratios and Inflammatory Cytokine Production in Patients with Chronic Heart Failure." Neuroimmunomodulation 11: 173-180.

22. Sternberg Z, Leung C, Sternberg D, Li F, Karmon Y, et al. (2013) The prevalence of the classical and non-classical cardiovascular risk factors in multiple sclerosis patients. CNS Neurol Disord Drug Targets 12: 104-111.

23. Berne-Fromell K, Fromell H, Lundkvist S, Lundkvist P (1987) Is multiple sclerosis the equivalent of Parkinson's disease for noradrenaline? Med Hypotheses 23: 409-415.

24. Szramka M, Harriss L, Ninnio D, Windebank E, Brack J, et al. (2007) The effect of rapid lipid lowering with atorvastatin on autonomic parameters in patients with coronary artery disease. Int J Cardiol 117: 287-291.

25. Neuhaus O, Stüve O, Zamvil SS, Hartung HP (2005) Evaluation of HMGCoA reductase inhibitors for multiple sclerosis: opportunities and obstacles. CNS Drugs 19: 833-841.

26. Birnbaum G, Cree B, Altafullah I, Zinser M, Reder AT (2008) Combining beta interferon and atorvastatin may increase disease activity in multiple sclerosis. Neurology 71: 1390-1395.

27. Bhat R, Axtell R, Mitra A, Miranda M, Lock C, et al. (2010) Inhibitory role for GABA in autoimmune inflammation. Proc Natl Acad Sci U S A 107: $2580-2585$

28. Taniyama K, Niwa M, Kataoka Y, Yamashita K (1993) Inhibition of the vesicular release of neurotransmitters by stimulation of $\mathrm{GABAB}$ receptor. Ann N Y Acad Sci 707: 496-499.

29. Suzdak PD, Gianutsos G (1985) Differential coupling of GABA-A and GABA-B receptors to the noradrenergic system. J Neural Transm 62: 77-89.

30. Yoshimura R, Ueda N, Hori H, Ikenouchi-Sugita A, Umene-Nakano W, et al. (2010) "Different Patterns of Longitudinal Changes in Plasma Levels of Catecholamine Metabolites and Brain-Derived Neurotrophic Factor After Administration of Atypical Antipsychotics in First Episode Untreated Schizophrenic Patients." The World Journal of Biological Psychiatry : The Official Journal of the World Federation of Societies of Biological Psychiatry 11: 256-261.

31. Kubota T, Hirota K, Yoshida H, Takahashi S, Anzawa N, et al. (1999) Effects of sedatives on noradrenaline release from the medial prefrontal cortex in rats. Psychopharmacology (Berl) 146: 335-338.

32. Brawek B, Löffler M, Dooley DJ, Weyerbrock A, Feuerstein TJ (2008) Differential modulation of $\mathrm{K}(+)$-evoked (3)H-neurotransmitter release from human neocortex by gabapentin and pregabalin. Naunyn Schmiedebergs Arch Pharmacol 376: 301-307.

33. de Saint Hilaire Z, Orosco M, Rouch C, Blanc G, Nicolaidis S (2001) "Variations in Extracellular Monoamines in the Prefrontal Cortex and Medial Hypothalamus After Modafinil Administration: A Microdialysis Study in Rats." Neuroreport 12: 3533-3537.

34. Nader ND, Ignatowski TA, Kurek CJ, Knight PR, Spengler RN (2001) "Clonidine Suppresses Plasma and Cerebrospinal Fluid Concentrations of TNF-Alpha during the Perioperative Period." Anes Analg 93: 363-369.

35. Borovikova LV, Ivanova S, Zhang M, Yang H, Botchkina GI, et al. (2000) Vagus nerve stimulation attenuates the systemic inflammatory response to endotoxin. Nature 405: 458-462.

36. Kox M, van Velzen JF, Pompe JC, Hoedemaekers CW, van der Hoeven JG, et al. (2009) "GTS-21 Inhibits Pro-Inflammatory Cytokine Release Independent of the Toll-Like Receptor Stimulated Via a Transcriptional Mechanism Involving JAK2 Activation." Biochem Pharmacol 78: 863-872.

37. van Westerloo DJ, Giebelen IA, Florquin S, Bruno MJ, Larosa GJ, et al. (2006) The vagus nerve and nicotinic receptors modulate experimental pancreatitis severity in mice. Gastroenterology 130: 1822-1830.

38. Giebelen IA, van Westerloo DJ, LaRosa GJ, de Vos AF, van der Poll T (2007) Local stimulation of alpha7 cholinergic receptors inhibits LPSinduced TNF-alpha release in the mouse lung. Shock 28: 700-703. 
Citation: Racosta JM, Kremenchutzky M (2014) The Role of Autonomic Dysregulation from Pathophysiology to Therapeutics of Multiple Sclerosis: A Putative Novel Treatment Target?. J Neurol Neurophysiol 5: 212. doi:10.4172/2155-9562-5-1000212

Page 4 of 4

39. Ku YT, Montgomery LD, Lee HC, Luna B, Webbon BW (2000) Physiologic and functional responses of MS patients to body cooling. Am J Phys Med Rehabil 79: 427-434.
40. Kinugasa H, Hirayanagi K (1999) Effects of skin surface cooling and heating on autonomic nervous activity and baroreflex sensitivity in humans. Exp Physiol 84: 369-377. 